\title{
CONTEXTO DO ENSINO DE FUNDAMENTOS TEÓRICOS DE BIBLIOTECONOMIA NA UFSC
}

THE TEACHING OF THEORETICAL FOUNDATIONS OF LIBRARY SCIENCE IN THE UFSC

\author{
FRANCISCO DAS CHAGAS DE SOUZA - Doutor em Educação \\ UFSC - Departamento de Ciência da Informação \\ Campus Universitário - Trindade \\ 88040-900 - Florianópolis, SC, Brasil \\ e-mail: chagas@,ced.ufsc.br, chagassouza@starmedia.com,souza@amja.org.br
}

\begin{abstract}
Resumo
Apresenta proposta didático-pedagógica - e seus fundamentos - em desenvolvimento no Currículo do Curso de Biblioteconomia da Universidade Federal de Santa Catarina, cuja execução se dá através da realização de seminários na disciplina Tópicos Especiais em Biblioteconomia a qual faz parte do núcleo disciplinar de Fundamentos Teóricos de Biblioteconomia.
\end{abstract}

Palavras-chave: ensino de biblioteconomia; prática e metodologia de ensino superior.

\section{INTRODUÇÃO}

$\mathrm{Na}$ análise da trajetória histórica do ensino superior são facilmente encontradas manifestações de alunos e de professores sobre as dificuldades na realização cotidiana do trabalho escolar, especialmente quando se trata da relação ensino / aprendizagem. Estas têm a ver com dois fenômenos que co-participam na relação professor-aluno, isto é, os conteúdos ensinados e os métodos e técnicas para a sua transmissão. Literatura dedicada à temática, dentre a qual a produzida por Gauthier e outros (1998), McLaren (1992) e Pacheco (1995), situa, em geral, no âmbito da atuação do docente a responsabilidade pela gestão tanto do conteúdo quanto da sala de aula.

Essas duas linhas de ação e atuação, complementares em si, são complexas o suficiente para fazerem emergir, e se transformarem em objeto de permanente discussão, as várias teorias educacionais que explicam e/ou fundamentam a ação / interação / atuação de professores e alunos. Também suscitam contínuas pesquisas e desenvolvimento de experiências no sentido da produção de teoria e de práticas de ensino capazes de tornar satisfatório para o professor o resultado de seu trabalho e para o aluno a sensação de ter professores que não apenas conhecem o conteúdo mas sabem transmiti-lo e torná-lo apreensível num dado tempo e espaço.

De outro lado, é fato notório, como se vê em Santos (1995), Leite (1998) e Jantzen (s.d.), por exemplo, que o ensino superior é realizado por não professores. Dito de outro 
modo, o professor de Ensino Superior em sua maioria, sendo titulado como bacharel, adquire uma formação que se dirige a uma atuação técnico-profissional, ou seja, para uma atuação não docente, e, por isso, não recebe a preparação necessária e completa para lidar com o ensino.

Em face dessas primeiras considerações, com este texto se deseja expor uma ação didático-pedagógica em desenvolvimento no Curso de Graduação em Biblioteconomia da UFSC, que objetiva fazer aproximações pedagógicas em pesquisa de ensino, tendo como meta testar a eficácia do uso predominante da técnica de seminário na disciplina Tópicos Especiais em Biblioteconomia, a partir do $2^{\circ}$. semestre de 2000 .

\section{FUNDAMENTOS EDUCACIONAIS E SOCIOLÓGICOS}

Em Ayala e Bohrer (s.d.) encontra-se uma discussão de como as tendências pedagógicas ou teorias educacionais adotadas no Brasil, após o início dos anos 1980, têm contribuído para que se busque formas alternativas e mais modernas para o ensino realizado no país. Do resultado de parte desta busca de alternativas, os autores afirmam que "falta uma configuração de concepções de currículo para a escola brasileira", o que leva a educação brasileira, como um todo, a ter necessidade de "construir uma teoria curricular mais condizente com a nossa realidade".

Essa construção curricular a ser empreendida, a fim de superar parcela de alienação e distanciamento do contexto vivido no país, é muito desejável quando diz respeito ao ensino universitário. Há estudos como os de Morosini e outros (2000), Veiga e Castanho (2000) e, especialmente, Leite e outros (1998) que, tratando da formação docente na universidade atual, observam que os valores e as práticas inerentes ao campo profissional, introjetados pelos profissionais das diversas áreas, são reproduzidos nas decisões de seu fazer docente o que traz para a ação didático-pedagógica os mecanismos de controle de conhecimento próprios de seu capital cultural e de sua competência científica.

Em essência, essa percepção reforça as explicações teóricas da sociologia profissional sustentada por Eliot Freidson (1998) sobre a tríade da atuação profissional, estruturada com base na: a) intervenção técnico-profissional; b) intervenção político-profissional, e c) intervenção educacional e em pesquisa. Sob esta perspectiva, a educação universitária é um campo inserido no conjunto das atribuições das profissões e deste modo a universidade é um ambiente a mais a ser utilizado como espaço de auto-afirmação social por cada uma das categorias profissionais. Esta é também uma visão que não se afasta da explicação teórica da construção social do conhecimento fornecida por Berger e Luckmann (1985). É que estes 
autores afirmam as profissões como papéis sociais que existem em construção e transformação constantes. E isto ocorre como parte da luta que determina a sua permanência social. Diante disso, percebe-se que profissões carecem de mecanismos de apoio dos quais a educação é um dos mais eficazes podendo ser considerada um motor de reprodução de quadros e de adaptação do sujeito profissional ao mundo concreto.

Se, como acima visto, é reproduzido no ensino universitário o pensamento das profissões e esse ensino é pouco controlado pelo pensamento pedagógico, que é construído por outra categoria profissional, a dos didatas e pedagogos, o que fazer? Santos (citado por Leite e outros, 1998) aponta para a auto-construção do docente como intelectual público que, independentemente de discursos pré-estabelecidos "tem nas questões sociais e políticas a ênfase pedagógica de seu trabalho". Para chegar a esta postura, sua formação depende do que pode ser obtido na universidade, por sua vez inserida dialeticamente na sociedade local e global. Portanto, a formação de futuros professores para o ensino superior depende de uma instituição de ensino universitário em condições de oferecer um currículo que contemple pelo menos três esferas do saber humano em ritmo de diálogo: a) senso comum; b) ciência, e c) crítica filosófica.

Isso aponta para a tendência internacional, suscitada ao longo da década de 1990, dirigida à construção de currículos não-lineares. Henriques (s.d.) contribui com esta discussão, partindo dos conceitos novos, originados na ciência física, de "complexidade" e "incerteza". Os fenômenos ligados a esses conceitos dificultam a sustentação no ensino superior da abordagem do mundo de uma forma homogênea, unidimensional, normativa, seqüencial, previsível e disciplinar, para usar os termos empregados pelo autor, como até recentemente predominou sem maiores questionamentos. Como resposta a esta estrutura positivista e regulada, Henriques (s.d.) sugere alguns parâmetros que poderiam orientar a definição de conteúdos preferenciais. A partir da adoção destes novos parâmetros (conhecimentos mais permanentes; potencial de descortinar outros campos; e desenvolvimento do potencial cognitivo dos alunos), evidencia-se uma necessidade, conforme o autor, que é "a introdução de novas perspectivas de ação docente, sob as quais devem ser pensadas as formas de organização das tarefas e do ambiente educativo..." Nessa situação, a relação aluno-professor seria de coordenação das experiências comuns às práticas de ensinar e aprender, articulando um currículo sob a lógica do conhecimento em rede e, por isso, "acentrado", isto é, "não faz sentido centrá-lo quer em disciplinas, quer no método, ou ainda no professor e no aluno". 
Essa relação dialética que coloca a universidade tradicional como arena das profissões, de um lado, e de outro, uma universidade pós-moderna (Santos, 1995) como construtora do intelectual público e de uma educação a-centrada, gera uma ampla produção de reflexões em torno da relação presumida do ensino, pesquisa e extensão como indissociáveis, por um lado, e por outro, como prenhe de experiências que podem ser inseridas na formação para uma dada profissão com forte perspectiva pedagógica. No primeiro caso, Cunha (s.d.) defende a idéia de que grande parte do ensino atual, por ser reprodutivo, impossibilita sua realização sem a construção de "um novo paradigma de ensinar e aprender na universidade." Dentre os argumentos apresentados, afirma a predominância ainda vigente da concepção positivista de ciência na estruturação dos currículos. Assim, constata que esses currículos, sob esta concepção, partem do geral para o específico; do abstrato para o concreto; do teórico para as práticas; do básico para o profissionalizante. Enfatiza, de outro lado, que mais recentemente há boas experiências em prática e, pode-se constatar que seu texto aqui citado, por exemplo, culmina com uma "proposta para a construção de currículos para os Cursos de Graduação da Universidade Federal de Pelotas".

$\mathrm{Na}$ âmbito das experiências é significativo, por exemplo, o relato de Jantsen (s.d.) sobre o assessoramento pedagógico que tem recebido de modo sistemático para o ensino de Teoria e História da Arquitetura na UFPel. Seu relato dá ênfase às etapas que precederam e que se seguiram à ministração daquela disciplina; à forma de aproximação com o assessoramento pedagógico e os limites que se colocam na construção de uma nova perspectiva de trabalho, como: "os limites da instituição; o significante da burocracia escolar; e os limites dos alunos". Por fim, Jantzen (s.d.) dá um passo teórico significativo, avançando da perspectiva do professor "profissionalista" para a do professor educador. Ele afirma: Através dessa tentativa consegui também compreender um aspecto essencial da pedagogia, que é aquilo que permite que ela seja tratada como uma das ciências sociais. Contrariando alguns colegas das ciências sociais, que a consideram uma ciência "vazia", sem conteúdo próprio, a pedagogia revela-se, para mim, como a grande produtora de conhecimentos, porque é, na sua essência, ação crítica e consciente.

\section{ENSINO DE BIBLIOTECONOMIA}

Várias áreas profissionais modernas, evoluíram de ocupações para profissões e estruturaram ou estabeleceram, notadamente a partir do século XIX, associações profissionais para projetarem e defenderem o futuro do respectivo campo. Isto gerou a percepção de que 
havia a necessidade de formulação e transmissão de conhecimento teórico e, por sua vez, criou as bases para a produção e publicação textual e para a organização do ensino profissional em condições de dar conta da progressiva complexidade que se ia estabelecendo a partir da prática e da experimentação. Pelewski (1971) fala assim da organização científica (ou moderna) do trabalho; Gomes e outros (1994) falam assim da relação verificada entre o embricamento dos campos profissionais de engenheiros e economistas. Nessa mesma direção, ou seja, de evolução de determinada atividade humana que passa de um estágio de ocupação para um estágio de profissão, de um saber prático para a construção de teoria, de uma aprendizagem em campo para a formação acadêmica, caminhou também a Biblioteconomia. Esse campo, como expressão de uma profissão formuladora de bases teóricas que podem ser utilizadas para a formação de quadros profissionais, se constituiu também como campo educacional a partir do século XIX, nos Estados Unidos da América, e subordinou-se à idéia da necessidade de reforçar a fixação e expansão de um papel social (a profissão em si) por meio da construção de uma identidade profissionalista. Para tanto, o campo educacional se estabeleceu a partir da mesma liderança, Melvil Dewey, que foi responsável pela criação do Library Jornal e da associação de classe, a American Library Association, conforme se vê nos textos de Miksa $(1986,1988)$ e de Asheim (1972). Desse modo, as matrizes teóricas da profissão e de sua educação derivam de uma mesma fonte. Isto sugere, como se deduz a partir dos escritos de Asheim (1972), que ocorreram iniciativas forjadas pela crença na necessidade de que "la preparación de los bibliotecarios tenia que evolucionar hacia una formación profesional seria y profunda, se es que se queria mantenerse a tono con la evolución cultural y social del país." (p. 171). Isso impõe como ações concretas o identificar e o construir uma ciência biblioteconômica. Tal tarefa foi concretamente apontada e inicialmente tentada em Chicago por Butler (1971), autor, em 1933, da primeira reflexão decorrente de investigação conceitual-teórica do que constitui a explicitação de uma fundamentação teóricoepistemológica da Biblioteconomia. A reforçar o ambiente norte-americano como berço dessa Biblioteconomia moderna, isto é, centrando certas ações no usuário e na gestão das informações sobre o acervo e seu uso, e, sobretudo do ensino de sua teoria, há o fato de que os Estados Unidos constituíram-se, por todo o século XX, de acordo com o que se constata nos estudos de Castells (1999), no que se pode chamar como o coração da economia capitalista e a maior economia industrial e de serviços do mundo, sendo superlativa em produção e consumo ainda segundo esta mesma análise. Deste ponto de vista, é possível afirmar que aquele país é um amplo usuário e processador de informação, o que faz surgir em seu meio todos os 
principais avanços tecnológicos que constituem a estrutura do que hoje se chama de sociedade da informação (Castells, 1999). Neste contexto, produção e inovação de conhecimento biblioteconômico se estabelecem como exigências imediatas e como condição para a permanência e futuro da profissão.

Decorre disso, que não dá para pesquisar o ensino de biblioteconomia e suas perspectivas para os anos próximos sem que se olhe para o movimento que ocorre naquele país, seja na educação, na pesquisa ou na ação profissional. No âmbito educacional, Haycock apresentou no $66^{\circ}$. Congresso Geral da IFLA, realizado em agosto de 2000, em Israel, uma contribuição versando sobre o Congresso Ensino Profissional de Biblioteconomia na América do Norte, isto é, nos Estados Unidos e no Canadá. Nesse Congresso participaram 150 delegados que analisaram:

". a complexidade da biblioteconomia no contexto das políticas de ensino superior;

. as pressões econômicas;

. as disparidades geográficas;

. o ensino das várias facetas da biblioteconomia;

. as mudanças demográficas na sociedade."

No referido Congresso Ensino Profissional de Biblioteconomia na América do Norte, organizado pela ALA, Bates discorrendo sobre o currículo de informação para o século XXI diz acreditar que um currículo dessa área para entrar o novo século deve fornecer:

". conhecimento em política e gestão em profundidade;

- um núcleo adequado de conhecimentos técnicos que enfatize: as pessoas (o que elas realmente precisam e não o que os bibliotecários acreditam que precisam); $\underline{\text { informação em }}$ qualquer meio; a tecnologia da informação.

- conhecimento sobre mídias não textuais (capacidade de gerar e aplicar padrões descritivos e linguagens de indexação para imagens, filmes, áudio, multimídia, Internet e bibliotecas digitais)."

Como se observa, é fortemente ressaltada como necessidade na educação profissional bibliotecária nos Estados Unidos a preparação para reconhecer o que as pessoas realmente precisam. Isto significa um adensamento do domínio de técnicas de investigação, tanto no âmbito acadêmico para a produção de teorização quanto no âmbito da gestão para fins de planejamento e de prestação de serviços.

Diferentemente deste quadro, há outra realidade bibliotecária e de ensino de biblioteconomia na América Latina. Lícia Arenas e Arenas Vargas, em texto publicado em 
2000 sobre a preparação de bibliotecários na América Latina, buscam literatura que fundamente uma análise sobre a constituição de comunidades científicas em biblioteconomia e ciência da informação. Essa perspectiva, assim colocada, situa ou presume a existência de um núcleo mediador da pesquisa na escola e nas exigências da sociedade como formuladora e usuária de conhecimento novo. Do conjunto desta literatura, em face do contexto em apreciação e diante do objetivo que as autoras pretendem atingir, é dado um destaque para o texto de Johnson. Para este autor, na América Espanhola e no Caribe "... existe uma tendência para ensinar o que os outros ensinam, em vez de inovar..." De acordo com ele, "Alguns dos currículos apresentados como novos [em um Encontro prévio de Educação e Investigação em Bibliotecología, Archivologia, Ciências da Informação e Documentação da América Ibérica e do Caribe, que se realizou em abril de 1998$]$ se caracterizam por estar com cerca de 20 anos de desatualização, exceto pela incorporação de algumas disciplinas sobre tecnologias da informação e da comunicação"

Essa defasagem se justifica, segundo o diagnóstico de Johnson, no fato de que "a maioria dos países da região têm economia predominantemente agrícola". Pode-se até acrescentar com base em textos de autores que também debatem a situação econômica da região, como Demo (s.d.), que o baixo percentual de indivíduos com poder aquisitivo para a aquisição de bens indica a impossibilidade de existência de um setor tecnológico forte. Com isso, onde há uma industrialização mais intensa na região, esta é tão dependente de partes e componentes vindos por meio de importações norte-americanas, européias e asiáticas que a tecnologia própria representa um percentual ínfimo. Com isso, as inovações sobre a base produtiva tendem a ser cosméticas e superficiais, pois o contexto econômico real não requer a mesma sofisticação que o contexto da América do Norte, por exemplo, o que implica um ambiente que fortalece a existência de uma baixa ou quase inexistente produção de teoria biblioteconômica na América Latina.

Já no âmbito da América do Sul e Brasil, há limitações nos investimentos em ciência e tecnologia, particularmente nos países que compõem o Mercosul, expressivamente apontadas por Soares (2001). Essas limitações, que reduzem substantivamente a geração de conhecimento novo inclusive para atender aos setores de produção econômica, contribuem para que se compreenda claramente as muitas limitações presentes também na geração de conhecimento biblioteconômico na região. Tais limitações são perceptíveis na literatura biblioteconômica do Mercosul e do Brasil. A esse respeito, o livro de construção coletiva Profissionais da Informação: formação, perfil e atuação profissional, de 2000, resultante das 
discussões sobre a evolução dos Encontros dos Diretores e Professores das Escolas de Biblioteconomia do MERCOSUL, resume, no geral, um esforço de revisão da literatura e a proposição de "soluções", pensadas ou criadas nos países de economia desenvolvida e quase totalmente embasadas na idéia chave MIP (Moderno Profissional da Informação), título e ideologia relativa ao tratamento e difusão de uma determinada categoria de informação, isto é, a informação para negócios, desenvolvidos ao longo dos anos 1990 pela FID.

De outro lado, mas influenciado pelo contexto de limitações da base econômica e dos investimentos em desenvolvimento aportados para a região, há historicamente um baixo investimento em investigação sobre o ensino de Biblioteconomia no Brasil. Em razão disso, como exemplo de investigação educacional em Biblioteconomia, subsiste quase apenas a produção realizada em programas de pós-graduação, inclusive os que abordam a educação brasileira como objeto de análise. Há, além disso, ações de pesquisa desenvolvidas em algumas escolas, podendo-se identificar estudos ou reflexões em andamento como os de Costa e Andrade (1999), sobre o ensino de biblioteconomia no estado do Ceará; Diniz (1999) sobre o ensino de Biblioteconomia no estado da Paraíba; Souza (1998, 1999, 2000) sobre o ensino de Biblioteconomia no estado de Santa Catarina, etc. Uma pesquisa acadêmica que, em Santa Catarina, se soma a este esforço de gerar conhecimento novo sobre o ensino de biblioteconomia, foi iniciada por Hillesheim (2001), cuja primeira produção foi apresentada em fevereiro de 2001, no Programa de Pós-Graduação em Educação - PPGE - da UFSC, como uma Dissertação de Mestrado intitulada "A prática pedagógica no Curso de Biblioteconomia da UFSC: discurso dos docentes do CIN e dos alunos do curso", tratando da interação professor - estudante de Biblioteconomia em sala de aula. Através dessa Dissertação, realizada com aplicação de metodologia qualitativa por meio de análise do Discurso do Sujeito Coletivo - DSC, é possível perceber que a dificuldade principal no ensino de biblioteconomia na UFSC - tomado como objetivo de investigação - se encontra mais no que a teoria pedagógica chama de gestão de sala (relação professor-aluno) do que na gestão do conteúdo. Essa perspectiva, importante em termos de formação profissional, tem sido desconsiderada no conjunto das discussões realizadas nos Encontros das Escolas de Biblioteconomia do Mercosul, uma vez que os documentos produzidos mostram que a ênfase tem sido dada majoritariamente à gestão do conteúdo.

\section{O ENSINO DE FUNDAMENTOS DE BIBLIOTECONOMIA NA UFSC EM TÓPICOS ESPECIAIS}


Tópicos Especiais é uma disciplina optativa no Currículo do Curso de Biblioteconomia. Foi criada com a finalidade de oferecer aos alunos um espaço para aproximação com "Temas atuais da Biblioteconomia". Geralmente, é ofertada na $3^{\mathrm{a}}$. ou $4^{\mathrm{a}}$. fases da grade curricular.

No segundo semestre de 2000 o tema abordado foi "Direitos Humanos do Leitor". Em 2000/1 o tema foi a "Sociedade da Informação" e em 2001/2 está sendo tratado "Cidadania e Informação".

Uma das características da disciplina é ser um espaço público, estendido para além da sala de aula convencional. Nesse sentido, uma das vias de contato integral da mesma com a sociedade é a manutenção de uma página na Internet em: http://www.ced.ufsc.br/bibliote/dep/Topicos2.htm. Outra característica é que o aluno não recebe conteúdos como objetivo principal. Ele recebe orientações de como organizar seus estudos sobre o tema. Para isto, há uma série de 10 Tópicos que são estudados em grupo para a geração, em trabalho coletivo, de uma monografia, uma exposição oral e debates. A expectativa é de que, pela prática do estudo reflexivo, os estudantes construam habilidades de análise e síntese de conteúdos, organização de exposições orais, preparação ao debate, treinamento de postura diante de platéia, habilidade ao trabalho em grupo e a noção de participação como trabalho efetivo. Toda a produção realizada ao longo da disciplina é avaliada, individual e coletivamente, e os resultados discutidos, como forma de provocar a compreensão de pontos fracos e fortes na construção e apresentação dos seminários. Por esta razão, no Plano de Ensino, o item que se refere à descrição da metodologia e avaliação é sempre extenso. Ali o estudante tem a noção do que está sendo considerado em seu desempenho.

Tendo isso em vista, pode-se dizer que se trata de uma disciplina que está transitando, pedagogicamente, do tradicional para o novo na medida em que a gestão, para além da sala e do conteúdo, é de um projeto de apropriação de conhecimento e de habilidades de como estudar e aprender.

Para implantar as propostas temáticas, tanto de 2000/2, quanto de 2001/1 e 2001/2, foi importante ter claro, de início, que se desejava testar uma alternativa que tivesse coerência com o teor da disciplina em cada um destes semestres. Ou seja, a dimensão metodológica das temáticas abordadas está centrada na discussão e compreensão de um projeto social, econômico e político do país, com implicações no universo comunicacional, no universo legal, etc. Para desenvolver a proposta, foi buscado um clássico da Metodologia de Ensino 
Superior, Bordenave e Pereira (1998), para apreensão das melhores possibilidades de incentivar a participação dos alunos. No caso do Curso de Biblioteconomia da UFSC, que se trata de Curso Noturno, no qual estudam alunos trabalhadores, era importante encontrar técnicas que lhes levassem a valorizar a participação em sala de aula, com produção em sala de aula, sem deixar para um segundo plano a realização de atividades extra-sala de aula. A necessidade disso tem duas razões: a) o individualismo onipresente que a dissertação de Hillesheim veio a demonstrar como uma atitude excessiva latente entre os alunos; b) a revalorização do coletivo, posto que a escola está formando futuros profissionais que precisam desenvolver durante a etapa de vivência acadêmica o sentido do trabalho coletivo como forma de construção do sentimento de solidariedade requerido na manutenção da corporação profissional, pela articulação das ações associativas, participação em grupos de trabalho, comissões de estudos profissionais, etc. Dentre as possíveis variantes metodológicas encontradas para a ministração da disciplina dentro das perspectivas apontadas (Phillips 66;

Díade; Tempestade Cerebral; Pergunta Circular; Grupos de Verbalização e de Observação; Painel; Simpósio; Dramatização; Seminário) foi escolhido o Seminário.

Os resultados em termos de desenvolvimento do trabalho de aprendizagem têm sido uma freqüência maior à biblioteca e um uso mais dinâmico da Internet como fonte de pesquisa e captação de textos. Aí se inclui como suporte o site "Educação Bibliotecária - sala de leitura do NIPEEB" em http://www.ced.ufsc.br/bibliote/dep/saleitura.html que se trata de uma Biblioteca Eletrônica fornecedora de acesso a publicações que disponibilizam textos integrais, desenvolvida no Departamento de Ciência da Informação da UFSC.

Nesse sentido, pode-se dizer que a proposta em andamento é eficaz em sua dimensão didático-pedagógica, de sociabilização, de não-linearidade, de participação dentro e fora de sala de aula, de publicização. Assim, pode-se observar que a disciplina Tópicos Especiais em Biblioteconomia do Curso de Biblioteconomia da UFSC, em 2000/2, 2001/1 e 2001/2 está se desenvolvendo sob a perspectiva de trabalhar com e para o contexto social, político e econômico do Curso de Biblioteconomia, colocando a universidade em uma dimensão mais ampla que uma instituição meramente dominada pelas profissões.

\section{CONSIDERAÇÕES FINAIS}

O caráter preliminar desta discussão, nos remete para o entendimento de que a educação bibliotecária ofertada ao alunado de biblioteconomia em escolas brasileiras, deve maximizar a discussão do contexto e dos valores básicos de construção da sociedade. Isso 
coloca como principal base teórica as questões sociais, as questões de cidadania ou, em outros termos, história, sociologia, psicologia, economia política e educação. Essa perspectiva, vista do ponto de vista pedagógico, necessariamente vai situar o aluno como co-autor do processo de ensino-aprendizagem e, por isso, vai inseri-lo na situação de auto-construtor de seu saber.

\begin{abstract}
It presents a didactic-pedagogical proposal in development in the Library Science undergraduated course of the Federal University of Santa Catarina, Brazil, realized in form of seminaries in the discipline "Special Topics in Librarianship."

Keywords: Library Science education; educational methodology

BIBLIOGRAFIA
\end{abstract}

ASHEIM, L. Escuelas de bibliotecologia em los Estados Unidos. In: KRAMER, G. (Comp.). Notas bibliotecológicas. México:.Pax-México, 1972. p. 166-172.

AYALA, E. J. Z.; BOHRER, C. R. S. As teorias educacionais como fonte das concepções de currículo: um estudo preliminar. Disponível em: $<$ http://www.ufsm.br/adeonline/ayala.html $>$ Acesso em: 28 jun. 2000.

BATES, M. F. Information Curriculum For The 21st Century. Disponível em:

$<$ http://www.ala.org/congress/bates_print.html $>$ Acesso em 5 set 2000.

BERGER, P.; LUCKMANN, Th. A construção social da realidade; tratado de Sociologia do Conhecimento. 6. ed. Petrópolis: Vozes, 1985.

BORDENAVE, J. D.; PEREIRA, A. M. Estratégias de ensino-aprendizagem. 10. ed. Petrópolis: Vozes, 1998.

BUTLER, P. Introducción a la biblioteconomia. México: Pax-México, 1971.

CASTELLS, M. A sociedade em rede. 2. ed. São Paulo: Paz e Terra, 1999.

COSTA, M. F. O.; ANDRADE, I. B. B. Reflexões curriculares do ensino de Biblioteconomia no Ceará.

Informação \& Sociedade: estudos. João Pessoa, v. 9, n. 2, 1999. Disponível em:

$<$ http://www.informacaoesociedade.ufpb.br> Acesso em 12 dez. 2000.

CUNHA, M. I. O currículo do ensino superior e a construção do conhecimento. Disponível em: $<$ http://www.unicamp.br/prg/forgrad/formem3j.html> Acesso em: 29 jun. 2000.

DEMO, P. Globalização da exclusão social; contradições teóricas e metodológicas do discurso neoliberal acerca do enfrentamento da pobreza. Disponível em:

$<$ http://redebonja.cbj.g12.br/ielusc/necom/textos/nec texto029.html $>$ Acesso em: 20 jul.2001.

DINIZ, E. S. Ensino de biblioteconomia na UFPB: questões curriculares. Informação \& Sociedade: estudos. João Pessoa, v.9, n.2, 1999. Disponível em: $<$ http://www.informacaoesociedade.ufpb.br> Acesso em: 12 dez. 2000.

FÉDÉRATION INTERNATIONALE D'INFORMATION ET DE DOCUMENTATION.

Information in the service of society. Disponivel em:

$<\underline{\text { http://www.kb.nl/infolev/fid/about/policy/index.html }>}$ 
FREIDSON, Eliot. Renascimento do profissionalismo: teoria, profecia e política. São Paulo: Ed. USP, 1998.

GAUTHIER, C. et al. Por uma teoria da Pedagogia; pesquisas contemporâneas sobre o saber docente. Ijuí: Ed. UNIJUI, 1998.

GOMES, A. C. G. (Org.). Engenheiros e economistas: novas elites burocráticas. Rio de Janeiro: Ed. FGV, 1994.

HAYCOCK, K. Le congrès sur l'enseignement professionnel en Amérique du Nord.

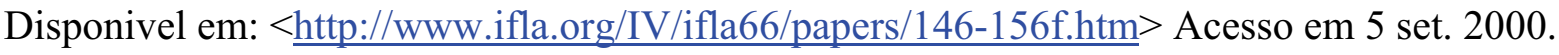

HENRIQUES, M. S. O pensamento complexo e a construção de um currículo não-linear. Disponível em: <http://www.ufrgs.br/faced/gtcurric/simeone.html> Acesso em 3 fev. 2000.

HILLESHEIM, A. I. A. A prática pedagógica no Curso de Biblioteconomia da UFSC: discurso dos docentes do CIN e dos alunos do curso. Florianópolis, 2001. 253p. Dissertação (Mestrado em Educação) - Programa de Pós-Graduação em Educação, Universidade Federal de Santa Catarina, Florianópolis, 2001. Disponível em:

$<$ http://www.ced.ufsc.br/bibliote/dep/resu araci.htm $>$

JANTZEN, S. A. D. Uma tentativa de produção do conhecimento. Disponível em: $<$ http://www.unicamp.br/prg/forgrad/formem3b.html > Acesso em: 29 jun.2000.

LEFEVRE, Fernando et al. $O$ discurso do sujeito coletivo: uma nova abordagem metodológica em

pesquisa qualitativa. Caxias do Sul: EDUCS, 2000.

LEITE, D. e outros. Formação do docente na universidade pós-moderna. Disponível em: $<$ http://www2.uca.es/HEURESIS/heuresis98/v1n2-1.html> Acesso em: 29 jun.2000.

LICEA DE ARENAS, J.; ARENAS VARGAS, M. La formación de comunidades científicas en bibliotecología y ciencia de la información. Anales de Documentación: R. de Bibliotecon. y Doc., n.3, 2000, p. 81-91. Disponível em: < http://www.um.es/fccd/anales/ad03/ad0300.html>.

MCLAREN, P. Rituais na escola; em direção a uma economia política de símbolos e gestos na escola. Petrópolis: Vozes, 1992.

MIKSA, F. L. Melvil Dewey: the professional educator and his heirs. Library Trends, v.34, n.3, p.359-379, 1986.

MIKSA, F. L. The Columbia School of Library Economy, 1887-1888. Libraries \& Culture, v. 23, n. 3, p.249-280, 1998.

MOROSINI, M. C. (Org.). Professor do ensino superior: identidade, docência e formação. Brasília: INEP, 2000.

PACHECO, J. A. O pensamento e a acção do professor. Porto: Porto Ed., 1995.

PALEWSKI, J.-P. A organização cientifica do trabalho. São Paulo: DIFEL, 1971.

SANTOS, B. S. Pela mão de Alice: o social e o político na pós-modernidade. São Paulo: Cortez, 1995.

SOARES, M. S. A. Ciência e tecnologia no Mercosul. In: BAUMGARTEN, M. (Org.). A era do conhecimento: Matrix ou Ágora. Porto Alegre:UFRGS; Brasília, Ed. UnB, 2001. p.245260. 
SOUZA, F. C. O sistema profissional bibliotecário brasileiro: sua capacidade de responder às mudanças do ambiente político e econômico no início do século XXI; uma abordagem sob a perspectiva da ação comunicativa. Encontros Bibli: revista de Biblioteconomia e Ciência da Informação, Florianópolis, n.10, out.2000. Disponível em:

$<$ http://www.ced.ufsc.br/bibliote/encontro/bibli10/francisco.htm>

SOUZA, F. C. A educação bibliotecária catarinense: causas de seus pontos fracos, entre 1973 e 1993. Encontros BIBLI: revista de Biblioteconomia e Ciência da Informação, Florianópolis, n.9, jun. 2000. Disponível em:

$<$ http://www.ced.ufsc.br/bibliote/encontro/bibli9/francisco.html $>$

SOUZA, F. C. Produção de literatura profissional e educação em informação documentária no Estado de Santa Catarina. Encontros BIBLI: revista de Biblioteconomia e Ciência da Informação, Florianópolis, n.8, set. 1999. Disponível em:

$<$ http://www.ced.ufsc.br/bibliote/encontro/bibli8/souza_rasche.html $>$

SOUZA, F. C. A educação de profissionais de informação documentária em Santa Catarina; relatório da pesquisa executada de dezembro de 1997 a outubro de 1998. Florianópolis: UFSC - Departamento de Biblioteconomia e Documentação, out. 1998. 40 f. + anexos (Realizada com apoio do FUNPESQUISA-UFSC)

SOUZA, F. C. A educação bibliotecária brasileira; comparação com a educação bibliotecária em alguns países europeus e asiáticos e uma proposta para atender a modernidade no Brasil. Florianópolis, 1997. 120 f. (Relatório de Pesquisa Apresentado ao Departamento de Biblioteconomia e Documentação).

VALENTIM, M. P. (Org.). Profissionais da informação: formação, perfil e atuação profissional. São Paulo: Polis, 2000.

VEIGA, I. P. A.; CASTANHO, M. E. L. M. (Orgs.). Pedagogia universitária: a aula em foco. Campinas: Papirus, 2000. 